\title{
Common themes in PrP signaling: the Src remains the
} same

\author{
Katharina Ochs and Edward Málaga-Trillo *t
}

Department of Biology, University of Konstanz, Konstanz, Germany

Edited by:

Jean-Luc Vilotte, National Institute of Agronomical Research, France

Reviewed by:

Mario Cioce, NYU Langone Medical

Center, USA

Husheng Ding, Mayo Clinic, USA

*Correspondence:

Edward Málaga-Trillo, Laboratorios de Investigación y Desarrollo,

Facultad de Ciencias y Filosofía,

Universidad Peruana Cayetano

Heredia, Av. Honorio Delgado 430,

Lima 31, Perú

e-mail:edward.malaga@upch.pe

${ }^{\dagger}$ Present address:

Edward Málaga-Trillo, Laboratorios de Investigación y Desarrollo,

Facultad de Ciencias y Filosofía, Universidad Peruana Cayetano

Heredia, Lima, Perú
The ability of the cellular prion protein $\left(\mathrm{Pr}^{\mathrm{C}}\right)$ to trigger intracellular signals appears central to neurodegeneration pathways, yet the physiological significance of such signals is rather puzzling. For instance, $\operatorname{PrPC}$ deregulation disrupts phenomena as diverse as synaptic transmission in mammals and cell adhesion in zebrafish. Although unrelated, the key proteins in these events -the NMDA receptor (NMDAR) and E-cadherin, respectively- are similarly modulated by the Src family kinase (SFK) Fyn. These observations highlight the importance of $\mathrm{PrPC}^{\mathrm{C}}$-mediated Fyn activation, a finding reported nearly two decades ago. Given their complex functions and regulation, SFKs may hold the key to intriguing aspects of PrP biology such as its seemingly promiscuous functions and the lack of strong phenotypes in knockout mice. Here we provide a mechanistic perspective on how SFKs might contribute to the uncertain molecular basis of neuronal PrP phenotypes affecting ion channel activity, axon myelination and olfactory function. In particular, we discuss SFK target proteins involved in these processes and the role of tyrosine phosphorylation in the regulation of their activity and cell surface expression.

Keywords: prion protein, Src family kinases, ion channels, myelination, tyrosine phosphorylation, endocytosis, knockout mice, zebrafish
Yes, there are two paths you can go by but in the long run

There's still time to change the road you're on

(R. Plant and J. Page)

\section{INTRODUCTION}

The abnormal accumulation of misfolded proteins is a defining molecular landmark of neurodegenerative conditions like prion, Alzheimer's and Parkinson's diseases. Interestingly, the identity of the pathogenic protein is different in each of these illnesses, suggesting that neurotoxicity may result from the excess of virtually any rogue protein in neuronal tissue. On the other hand, at least some of these proteins may play physiological roles in their nonaggregated state, which are key to neuronal survival and disease. For instance, the amyloid precursor protein and $\alpha$-synucleinthe protein culprits of Alzheimer's and Parkinson's disease-are enriched in neuronal synapses and nerve terminals (Maroteaux et al., 1988; Schubert et al., 1991). Likewise, expression of $\operatorname{PrP}^{\mathrm{C}}$ on neuronal cell surfaces is required for pathogenic prions and a $\beta$ oligomers to trigger cellular damage (Chesebro et al., 2005; Um et al., 2012). Beyond their propensity to misfold and aggregate, little is known about how exactly these proteins contribute to neuronal physiology and disease. For PrP, the quest for a gene/protein function has been particularly challenging because of the paucity of clear knockout phenotypes in mice (Steele et al., 2007). While this phenomenon may be explained by compensatory mechanisms (Málaga-Trillo and Sempou, 2009), the actual extent to which other genes can functionally replace PrP is only partly understood (Passet et al., 2013). More recent analyses of
PrP knockout mice have revealed subtle defects in axon myelination and olfactory function as well as in the proliferation of neural precursors and self-renewal of hematopoietic stem cells (Steele et al., 2006; Zhang et al., 2006; Le Pichon et al., 2009; Bremer et al., 2010). Unfortunately, the precise molecular basis of these phenotypes remains unclear. Adding complexity to the matter, many of the dissimilar functions and interaction partners proposed for $\operatorname{PrP}^{\mathrm{C}}$ cannot easily be accounted for by a single biological activity.

Among the various molecular roles ascribed to $\operatorname{PrP}^{\mathrm{C}}$, its ability to elicit intracellular signals is in good correspondence with its cell surface localization and involvement in physiological processes as diverse and complex as cell adhesion, lymphocyte activation, neuroprotection, and synaptic function (Aguzzi et al., 2008). That PrP signaling is pathophysiologically relevant was elegantly shown by Chesebro and colleagues, who demonstrated that without anchoring to the plasma membrane, PrP may misfold and aggregate but not induce neuronal damage (Chesebro et al., 2005). Presently, a number of transmembrane and intracellular molecules are known to help $\operatorname{PrP}^{\mathrm{C}}$ transduce signals into the cell's interior (Linden et al., 2008). Among the latter, SFKs have gathered renewed interest because of their connection to prionand $\mathrm{a} \beta$-induced neurotoxicity as well as for their contribution to PrP-mediated cell communication in vivo. The purpose of this article is to revisit putative functions of $\operatorname{PrP}$ in the context of SFK signaling.

\section{SFKs, A MULTIFUNCTIONAL PROTEIN FAMILY}

The Src family of non-receptor protein tyrosine kinases comprises nine members in vertebrates, five of which are active in 
mammalian CNS neurons, namely the ubiquitously expressed Src, Fyn, and Yes, and the tissue-restricted Lck and Lyn (Thomas and Brugge, 1997; Salter and Kalia, 2004). Their association to the cytoplasmic face of the plasma membrane via myristoylation and palmytoylation enables them to receive extracellular stimuli and transduce them into the cell interior (Silverman et al., 1993). SFK enzymatic activity is triggered by autophosphorylation at tyrosine residue 416 and inhibited by phosphorylation of tyrosine residue 527 (Roskoski, 2005). Owing to their interaction with a diverse array of transmembrane receptors and downstream targets, SFKs can regulate a broad range of cellular processes, including cell differentiation, proliferation, adhesion, migration, apoptosis, and immunity (Thomas and Brugge, 1997; Roskoski, 2004). Because of their strong structural conservation, SFK members are functionally redundant and can often compensate for each other, encumbering analysis of their individual roles via gene knockout approaches (Lowell and Soriano, 1996). Given their expression and multiple functions in neurons, it is not surprising that SFK deregulation should contribute to neurodegeneration. In fact, prion infection triggers increased levels of Src and phosphotyrosine proteins in cultured cells and mice (Nixon, 2005; Gyllberg et al., 2006). Moreover, Fyn is selectively upregulated in Alzheimer's brains (Shirazi and Wood, 1993), where it mediates hyperphosphorylation of the aggregation-prone, microtubuleassociated protein Tau (Lee et al., 2004). Fittingly, Fyn overexpression triggers synaptic damage in mouse models of Alzheimer's disease (Chin et al., 2005) whereas Fyn knockdown leads to decreased Tau phosphorylation, increased a $\beta$ levels and impaired spatial learning (Minami et al., 2012). Together, these findings imply a direct involvement of SFKs in neurotoxic pathways that are common to multiple neurodegenerative conditions.

\section{SFKs AS FUNCTIONAL HUBS OF PrP}

Being tethered to the outer leaflet of the plasma membrane via a short glycosylphosphatidylinositol- (GPI) anchor, PrP is unlikely to physically associate with cytosolic SFKs. Nevertheless, co-immunoprecipitation data indicate that, in epithelial cells, PrP and SFKs interact at least indirectly within a larger protein complex (Morel et al., 2004, 2008). In addition, plenty of evidence supports the notion that $\operatorname{PrP}$ and SFKs are functional partners in neurons. Using antibody-mediated crosslinking, Mouillet-Richard and colleagues were the first to show that PrP clustering at neuronal cell surfaces triggers caveolindependent activation of Fyn (Mouillet-Richard et al., 2000). Related experiments in neuron-like PC12 cells corroborated the contribution of caveolin to $\mathrm{PrP}^{\mathrm{C}}$-mediated Fyn activation, along with the downstream activation of the Ras-Raf/ERK pathway and the negative regulation of the entire cascade by phosphocaveolin (Pantera et al., 2009). In cultured mouse hippocampal neurons, $\operatorname{PrP}^{\mathrm{C}}$ was found to indirectly activate Fyn via cis or trans associations with the neural cell adhesion molecule (NCAM) within lipid rafts, thereby stimulating neurite outgrowth (Santuccione et al., 2005). Importantly, in vivo data from a wide range of animal models underscore the relevance of the PrP/SFK pathway in physiology and disease. For instance, expression of a pathogenic PrP mutant in Caenorhabditis elegans induced neuronal dysfunction in a Fyn-dependent manner
(Bizat et al., 2010), a remarkable result since nematodes do not possess endogenous PrPs. In early zebrafish embryos, exogenously added mouse PrP mimicks the positive regulation of E-cadherin-mediated cell adhesion by endogenous PrPs, an effect that requires Fyn and Yes activity (Málaga-Trillo et al., 2009; Sempou et al., submitted). In undoubtedly one of the most sensational developments in the recent field of neurodegeneration, neuronal $\operatorname{PrP}^{\mathrm{C}}$ was reported to act as a receptor for $\mathrm{a} \beta$ oligomers. Notably, the resulting synaptic impairment was mediated by Fyn (Um et al., 2012).

At first glance, some of these findings have no apparent connection with each other, aside from the common involvement of SFKs. However, closer scrutiny reveals mechanistic similarities pertinent to our understanding of $\operatorname{PrP}$ function. This is particularly manifest in two of the aforementioned models, where the downstream targets of PrP turned out to be transmembrane proteins modulated by tyrosine phosphorylation. In the study by the Strittmatter lab, binding of a $\beta$ oligomers to $\mathrm{PrP}^{\mathrm{C}}$ triggered Fyn activation and hyperphosphorylation of the NR2B subunit of the NMDAR at tyrosine residue 1472 (Um et al., 2012). As a result, NMDARs became overstabilized at the plasma membrane and glutamate excitotoxicity ensued. Under non-pathological conditions, phosphorylation of NR2B at this C-terminal regulatory site promotes its normal cell surface expression by preventing the binding of AP-2 adaptor complexes, which would otherwise initiate its internalization via clathrin- and dynamin-dependent endocytosis (Salter and Kalia, 2004). Similarly, postsynaptic density protein 95 (PSD-95) prevents NR2B endocytosis by binding a site adjacent to tyrosine 1472 and thereby blocking access to AP-2 (Lavezzari et al., 2003). Overall, the phosphorylation state of NMDAR subunits is controlled by the dynamic interplay between SFKs and protein tyrosine phosphatases (PTPs), as well as by the input from various upstream signaling molecules (Salter and Kalia, 2004). In addition, NMDAR function is further regulated via differential transcription, translation and trafficking of specific subunits as well as through protein-protein interactions (Sanz-Clemente et al., 2013). Notably, the regulation of protein endocytosis by molecules that competitively bind target motifs at cytoplasmic tails is also pivotal to the modulation of E-cadherin cell surface expression (Ishiyama et al., 2010). Thus, association of p120 catenin to the C-terminal juxtamembrane domain (JMD) of E-cadherin sterically blocks binding of AP-2 and the E3 ubiquitin ligase Hakai, thereby preventing its clathrinmediated or ubiquitination-dependent endocytosis, respectively (Thoreson et al., 2000; Fujita et al., 2002; Miyashita and Ozawa, 2007; Ishiyama et al., 2010). Importantly, SFK-mediated phosphorylation of the JMD and/or p120 catenin triggers E-cadherin internalization (Reynolds, 2010). Additionally, SFKs phosphorylate and modulate components of the endocytic machinery like clathrin, dynamin and AP-2 (Ahn et al., 1999, 2002; Wilde et al., 1999; Zimmerman et al., 2009). In our zebrafish model, $\operatorname{PrP}^{\mathrm{C}}$ promotes embryonic cell adhesion by stabilizing E-cadherin at the cell-surface (Málaga-Trillo et al., 2009). Crucially, this activity entails the SFK-dependent inhibition of E-cadherin endocytosis (Sempou et al., submitted). Therefore, the roles of $\mathrm{PrP}^{\mathrm{C}}$ as a modulator of cell-cell adhesion in zebrafish and synaptic transmission in mammals converge at a common mechanism, 
namely the ability of SFKs to control the internalization of transmembrane proteins by phosphorylating their endocytic signals and/or the corresponding binding molecules. Given the functional diversity of SFK target proteins, we reasoned that altered SFK activity may account for at least some of the distinct neuronal phenotypes observed in PrP knockout and transgenic mice (Figure 1, Table 1). To address this possibility, we examined three compelling, yet poorly understood paradigms of $\operatorname{PrP}$ function.

\section{PrP AND ION CHANNELS}

The NMDAR-mediated glutamate excitotoxicity induced by a $\beta$ oligomers and $\mathrm{PrP}^{\mathrm{C}}$ clearly shows that the latter can influence the activity of ion channels (Um et al., 2012). Intriguingly, while this effect relies on the PrP-dependent overactivation of NR2B subunits, a different study found that $\operatorname{PrP}^{\mathrm{C}}$ suppresses NMDAR activity and glutamate excitotoxicity via the inhibition of NR2D subunits (Khosravani et al., 2008). How PrP may influence this pathway under physiological conditions remains to be established. Nonetheless, a general role of $\operatorname{PrP}$ as a modulator of ion channel activity and neurotransmission is consistent with its synaptic localization (Moya et al., 2000; Um et al., 2012) and the common occurrence of electrophysiological alterations in $\operatorname{PrP}$ knockout mice (Aguzzi et al., 2008; Biasini et al., 2012). Moreover, transgenic mice expressing neurotoxic PrP mutants show distinct neurological phenotypes related to ion channel dysfunction. One of these mutants, PrP $\Delta C R$, has 21 aa deleted from its central region and triggers neonatal lethality characterized by the spontaneous degeneration of cerebellar granule neurons (CGNs) (Li et al., 2007). Subsequent work in cultured cells and cerebellar slices revealed that $\operatorname{PrP} \triangle \mathrm{CR}$ induces spontaneous currents that increase neuronal susceptibility to glutamate-dependent, $\mathrm{Ca}^{2+}$. mediated excitotoxicity (Solomon et al., 2010; Biasini et al., 2013). Based on these data, the authors suggested that $\operatorname{PrP} \Delta C R$ might either activate an endogenous ion channel or form itself an ion channel. A second PrP mutant, PG14, causes age-related degeneration of CGNs owing to defective glutamate exocytosis and impaired calcium dynamics (Senatore et al., 2012). This phenotype was explained by the ability of PG14 to bind the voltage-gated calcium channel (VGCC) $\alpha_{2} \delta-1$ subunit and retain

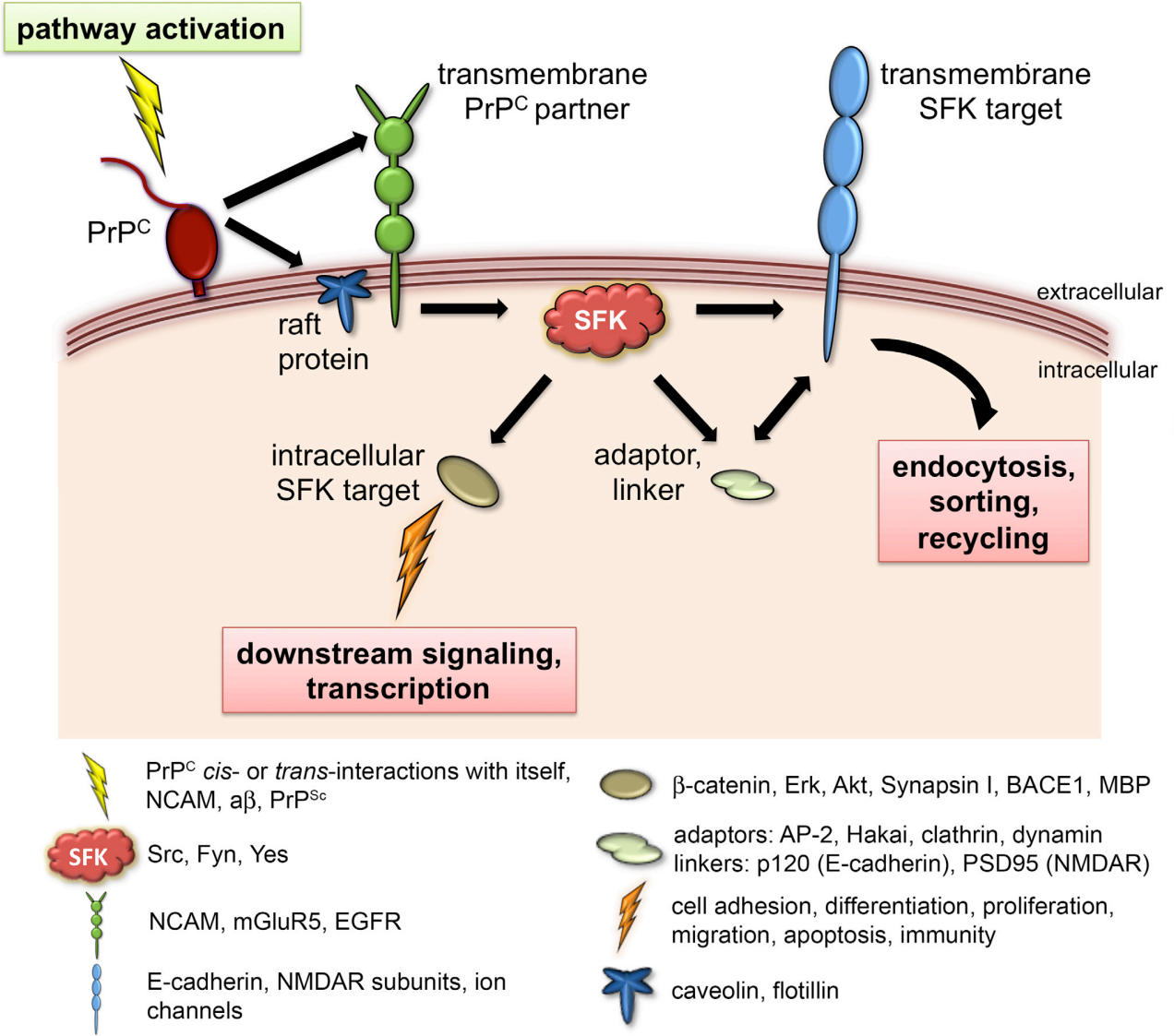

FIGURE 1 | PrPC signaling via SFKs. Known physiological roles of $\operatorname{PrP}^{\mathrm{C}}$ such as neurotransmission, embryonic cell adhesion, olfactory function, and myelination converge at the use of SFKs as intracellular signaling partners. In this model, engagement of $\mathrm{PrPC}^{\mathrm{C}}$ in various cis- or trans-interactions (depicted as "pathway activation") elicits the catalytic activity of SFKs, leading to the modulation of diverse downstream targets that include ion channels, adhesion

complexes, and cytosolic signaling molecules. Phosphorylation of transmembrane SFK targets controls their cell surface expression and/or signaling properties, whereas phosphorylation of intracellular SFK targets regulates the activation of additional downstream pathways, gene transcription, and protein translation. The caption below provides concrete examples of documented components of this cascade. 
Table 1 | SFKs and downstream events involved in PrP activities.

\begin{tabular}{|c|c|c|c|}
\hline PrP activities reported & SFKs involved & SFK target events affected & References \\
\hline $\begin{array}{l}\text { Regulation of embryonic cell } \\
\text { adhesion (zebrafish) }\end{array}$ & Fyn, Yes & Endocytosis of E-cadherin & Ishiyama et al., 2010 \\
\hline $\operatorname{PrP} \Delta \mathrm{CR}$ neurotoxicity & Fyn & Gating and/or endocytosis of NMDARs & Salter and Kalia, 2004 \\
\hline PrP PG14 neurotoxicity & Src & Gating and/or endocytosis of VGCCs & Davis et al., 2001 \\
\hline & Fyn & Gating and/or endocytosis of NMDARs & $\begin{array}{l}\text { Chen et al., 2000; Halabisky et al., } \\
2000\end{array}$ \\
\hline \multirow[t]{3}{*}{ Molecular control of myelination } & Src & Activation of Akt/PKB & $\begin{array}{l}\text { Chen et al., 2001; Jiang and Qiu, } \\
2003\end{array}$ \\
\hline & unknown & Endocytosis of MAG and MOG & $\begin{array}{l}\text { Bo et al., 1995; Kroepfl and } \\
\text { Gardinier, 2001a,b }\end{array}$ \\
\hline & Src, Fyn & Gating and/or endocytosis of $K_{v} 1.5$ and 2.1 channels & $\begin{array}{l}\text { Sobko et al., 1998; Peretz et al., } \\
\text { 1999; Tiran et al., } 2006\end{array}$ \\
\hline
\end{tabular}

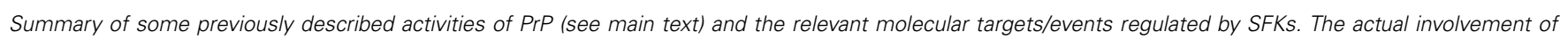

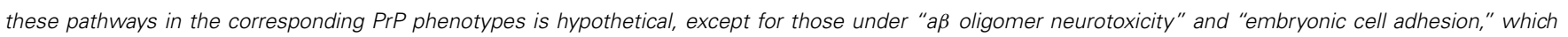
have been experimentally confirmed.

it at the ER, thus disrupting its delivery to the plasma membrane. Notably, while the molecular mechanisms of these two phenotypes seem unrelated, they are both consistent with the ability of SFKs to regulate the activity of ligand- and voltage-gated ion channels (Salter and Kalia, 2004). For instance, the spontaneous ionic currents induced by $\operatorname{PrP} \Delta \mathrm{CR}$ may be explained by alterations in SFK-mediated phosphorylation and trafficking of NMDAR subunits. Detailed biochemical analyses will be needed to distinguish between this scenario and one proposed by the authors, namely, that the mutant PrP molecule activates NMDARs via direct interaction (Biasini et al., 2013). For the PG14 phenotype, the data show that intracellular retention of VGCC $\alpha_{2} \delta-1$ during biosynthesis is the most likely explanation for its reduced levels at the plasma membrane (Senatore et al., 2012). However, here it also might be worthwhile considering that VGCCs are modulated via tyrosine phosphorylation by, among others, Src (Davis et al., 2001). Whether SFK regulation of VGCCs targets their trafficking or only their gating properties is presently unknown.

\section{PrP AND OLFACTION}

Unique among mouse PrP knockout phenotypes was the finding of impaired olfactory behavior (Le Pichon et al., 2009). In electrophysiological terms, the phenotype was attributed to olfactory bulb-specific alterations in the patterns of oscillatory activity and in the plasticity of the dendrodendritic synapse. No molecular basis was reported for these defects but the authors suggested that due to its localization at olfactory synaptic membranes and its interaction with Synapsin Ib (Spielhaupter and Schatzl, 2001), PrP may be a regulatory component of the synaptic machinery. Interestingly, several lines of evidence argue for a contribution of SFKs and their targets to this phenotype. First, phosphorylation of Synapsin I by Src increases its binding to synaptic vesicles (SVs) and the actin cytoskeleton, thereby limiting the number of recycled SVs available for exocytosis and neurotransmitter release (Messa et al., 2010). Second, Fyn-deficient mice exhibit defects related to the olfactory dysfunction described by Le Pichon et al., such as impaired suckling behavior, altered synaptic transmission via GABA and NMDA receptors in the olfactory bulb, and abnormal axon guidance and fasciculation in the olfactory nerve (Yagi et al., 1993; Kitazawa et al., 1998; Morse et al., 1998). Third, $\mathrm{K}_{\mathrm{V}} 1.3$ voltage-gated potassium channels are expressed along the dendrodendritic synapse and are negatively regulated by Src phosphorylation (Fadool and Levitan, 1998; Fadool et al., 2000). Remarkably, olfactory neurons from $\mathrm{K}_{\mathrm{V}} 1.3$ null mice have modified action potentials and deregulated potassium currents, resulting in structurally altered olfactory bulbs and a heightened sense of smell (Fadool et al., 2004). Fourth, NMDARs play a crucial role at the dendrodendritic synapse by generating the $\mathrm{Ca}^{2+}$ influx that triggers inhibitory GABA release (Chen et al., 2000; Halabisky et al., 2000). This essential component of olfactory learning is therefore also subject to modulation by PrP and SFKs. Hence, the combined, SFK-mediated deregulation of Synapsin I, $\mathrm{K}_{\mathrm{V}} 1.3$ channels, and NMDARs provides testable explanations for the olfactory defects of PrP knockout mice. 


\section{PrP AND MYELINATION}

Re-examination of a mild, late-onset phenotype in PrP knockout mice led to the discovery of defects in the maintenance of peripheral myelin (Bremer et al., 2010). This chronic demyelinating polyneuropathy (CDP) was triggered by the loss of PrP in neurons but not in Schwann cells. The mechanistic basis of this phenotype remains unidentified, as the authors found no alterations in the phosphorylation of Akt, and Erk, two signaling molecules down the myelination pathway initiated with the cleavage of Neuregulin-1 (NRG1) by the BACE1 endopeptidase (Hu et al., 2006; Liu et al., 2007). Similarly, no differences were detected in the expression levels of NRG1, although, neither BACE1 activity nor BACE1-mediated cleavage of NRG1 was directly assessed in PrP knockout mice. Interestingly, Src is known to modulate several events along the BACE1/NRG1 pathway. Some of them, like Akt phosphorylation by Src (Chen et al., 2001; Jiang and Qiu, 2003), are probably not involved in the PrP phenotype, as implied by Bremer and colleagues. Others like BACE1 endocytosis and activation (Zou et al., 2007) or the mTORC1-induced transcription of the myelin basic protein (MBP) gene (Vojtechova et al., 2008; Ondrusova et al., 2013) would require further verification. Of note, BACE-null mice exhibit myelination defects reminiscent of those in PrP knockout mice, as well as increased levels of full-length NRG1 and-unlike PrP knockouts-reduced Akt phosphorylation (Hu et al., 2006, 2008).

As with the olfactory phenotype of Le Pichon et al., copious evidence suggests a potential involvement of SFKs in the PrP-CDP phenotype. Comprehensive reviews on the role of Fyn during myelination are available elsewhere (Kramer-Albers and White, 2011; White and Kramer-Albers, 2014) but for example, myelination requires Fyn activation by the myelin-associated glycoprotein (MAG), and activated Fyn promotes MBP gene transcription (Umemori et al., 1994, 1999). In addition, Fyn stimulates the localized translation of MBP mRNA at sites of axon-glia contact via phosphorylation of the heterogeneous nuclear ribonucleoprotein (hnRNP) A2 (White et al., 2008). Furthermore, Fyn-deficient mice show myelination defects similar to those of BACE- and PrPnull mice, albeit with some differences in the localization (PNS vs. CNS), onset (late vs. early) and severity of the phenotype (Umemori et al., 1994, 1999; Sperber et al., 2001). Interestingly, the presence of tyrosine-based endocytic motifs in MAG and the myelin/oligodendrocyte glycoprotein (MOG) strongly suggests that their cell surface expression is modulated by SFKs (Bo et al., 1995; Kroepfl and Gardinier, 2001a,b). In fact, the endocytic trafficking and sorting of myelin proteins is key to the establishment of membrane domains in oligodendroglial cells (Winterstein et al., 2008). Particularly relevant to the PrP-CDP phenotype, adult and aged MAG-null mice undergo degeneration of myelinated fibers in the PNS (Schachner and Bartsch, 2000).

Finally, voltage- and ligand-gated ion channels constitute further regulatory targets of SFKs during myelination. For instance, the phosphorylation state of $K_{v} 1.5$ and $K_{v} 2.1$ potassium channels in Schwann cells is controlled by the interplay between Src, Fyn, PTP $\alpha$, and PTPE (Sobko et al., 1998; Peretz et al., 1999; Tiran et al., 2006). This complex mechanism modulates the gating properties of the channels, influencing Schwann cell development and the onset of myelination. Likewise, NMDARs promote the maturation of oligodendrocyte precursor cells (OPCs) by enhancing the expression of myelin proteins ( $\mathrm{Li}$ et al., 2013). Nevertheless, experiments with NMDAR-deficient mice suggest that, in vivo, this regulation might be relevant for re-myelination but not for OPC development (De Biase et al., 2011; Li et al., 2013). Thus, although the molecular control of myelination is a rather intricate phenomenon, the PrP-CDP phenotype seems consistent with the alteration of multiple pathways downstream of SFKs.

Altogether, the common regulation of ion channels, olfaction and myelination by PrP and SFKs suggests that this phenomenon may extend to some of the other subtle PrP phenotypes mentioned above. For instance, it would be interesting to see if the role of $\mathrm{PrP}^{\mathrm{C}}$ in the proliferation and differentiation of various stem cell lineages (reviewed in Martin-Lannerée et al., 2014) requires the differential expression of SFKs and their targets at specific stages of stem cell maturation. Along these lines, the contribution of tissue-restricted SFKs to PrP signaling deserves further investigation, as most of the available data on the PrP/SFK pathway so far involve only the ubiquitously expressed Src, Fyn, and Yes.

\section{CONCLUSIONS}

Several key observations emerge from the present analysis. First, the ability of $\operatorname{PrP}^{\mathrm{C}}$ to elicit intracellular signals at the cell surface is central to its multiple roles in health and disease. Second, the specificity of these signals is largely determined by extrinsic factors such as the plasma membrane microenvironment and the availability of cell- and tissue-specific protein partners. Third, the ubiquitous expression and functional redundancy of SFKs, along with the diversity of their downstream targets offer plausible explanations for some of the striking facts of PrP biology, such as its functional promiscuity, the viability of $\operatorname{PrP}$ knockout mice, and the diversity of PrP transgenic/mutant phenotypes. Based on these considerations, we propose that $\operatorname{PrP}^{\mathrm{C}}$ acts as a gatekeeper between neuronal survival and toxicity by controlling the activity and/or endocytic trafficking of ion channels, synaptic proteins and cell adhesion molecules via SFKs. Testing these complex scenarios should prove a formidable but rewarding endeavor.

\section{ACKNOWLEDGMENTS}

Our warm gratitude to Florence Kranitz and the CJD Foundation for their kind support. Special thanks to Chuck for his dogged encouragement. Funded by the Deutsche Forschungsgemeinschaft (Grant MA 2525/1-1) and the University of Konstanz AFF.

\section{REFERENCES}

Aguzzi, A., Baumann, F., and Bremer, J. (2008). The prion's elusive reason for being. Annu. Rev. Neurosci. 31, 439-477. doi: 10.1146/annurev.neuro.31.060407.125620

Ahn, S., Kim, J., Lucaveche, C. L., Reedy, M. C., Luttrell, L. M., Lefkowitz, R. J., et al. (2002). Src-dependent tyrosine phosphorylation regulates dynamin self-assembly and ligand-induced endocytosis of the epidermal growth factor receptor. J. Biol. Chem. 277, 26642-26651. doi: 10.1074/jbc.M201499200

Ahn, S., Maudsley, S., Luttrell, L. M., Lefkowitz, R. J., and Daaka, Y. (1999). Srcmediated tyrosine phosphorylation of dynamin is required for beta2-adrenergic receptor internalization and mitogen-activated protein kinase signaling. J. Biol. Chem. 274, 1185-1188. doi: 10.1074/jbc.274.3.1185 
Biasini, E., Turnbaugh, J. A., Unterberger, U., and Harris, D. A. (2012). Prion protein at the crossroads of physiology and disease. Trends Neurosci. 35, 92-103. doi: 10.1016/j.tins.2011.10.002

Biasini, E., Unterberger, U., Solomon, I. H., Massignan, T., Senatore, A., Bian, H., et al. (2013). A mutant prion protein sensitizes neurons to glutamate-induced excitotoxicity. J. Neurosci. 33, 2408-2418. doi: 10.1523/JNEUROSCI.340612.2013

Bizat, N., Peyrin, J. M., Haik, S., Cochois, V., Beaudry, P., Laplanche, J. L., et al. (2010). Neuron dysfunction is induced by prion protein with an insertional mutation via a Fyn kinase and reversed by sirtuin activation in Caenorhabditis elegans. J. Neurosci. 30, 5394-5403. doi: 10.1523/JNEUROSCI.5831-09.2010

Bo, L., Quarles, R. H., Fujita, N., Bartoszewicz, Z., Sato, S., and Trapp, B. D. (1995). Endocytic depletion of L-MAG from CNS myelin in quaking mice. J. Cell Biol. 131, 1811-1820. doi: 10.1083/jcb.131.6.1811

Bremer, J., Baumann, F., Tiberi, C., Wessig, C., Fischer, H., Schwarz, P., et al. (2010). Axonal prion protein is required for peripheral myelin maintenance. Nat. Neurosci. 13, 310-318. doi: 10.1038/nn.2483

Chen, R., Kim, O., Yang, J., Sato, K., Eisenmann, K. M., Mccarthy, J., et al. (2001). Regulation of Akt/PKB activation by tyrosine phosphorylation. J. Biol. Chem. 276, 31858-31862. doi: 10.1074/jbc.C100271200

Chen, W. R., Xiong, W., and Shepherd, G. M. (2000). Analysis of relations between NMDA receptors and GABA release at olfactory bulb reciprocal synapses. Neuron 25, 625-633. doi: 10.1016/S0896-6273(00)81065-X

Chesebro, B., Trifilo, M., Race, R., Meade-White, K., Teng, C., Lacasse, R., et al. (2005). Anchorless prion protein results in infectious amyloid disease without clinical scrapie. Science 308, 1435-1439. doi: 10.1126/science.1110837

Chin, J., Palop, J. J., Puolivali, J., Massaro, C., Bien-Ly, N., Gerstein, H., et al. (2005). Fyn kinase induces synaptic and cognitive impairments in a transgenic mouse model of Alzheimer's disease. J. Neurosci. 25, 9694-9703. doi: 10.1523/JNEUROSCI.2980-05.2005

Davis, M. J., Wu, X., Nurkiewicz, T. R., Kawasaki, J., Gui, P., Hill, M. A., et al. (2001). Regulation of ion channels by protein tyrosine phosphorylation. Am. J. Physiol. Heart Circ. Physiol. 281, H1835-H1862.

De Biase, L. M., Kang, S. H., Baxi, E. G., Fukaya, M., Pucak, M. L., Mishina, M., et al. (2011). NMDA receptor signaling in oligodendrocyte progenitors is not required for oligodendrogenesis and myelination. J. Neurosci. 31, 12650-12662. doi: 10.1523/JNEUROSCI.2455-11.2011

Fadool, D. A., and Levitan, I. B. (1998). Modulation of olfactory bulb neuron potassium current by tyrosine phosphorylation. J. Neurosci. 18, 6126-6137.

Fadool, D. A., Tucker, K., Perkins, R., Fasciani, G., Thompson, R. N., Parsons, A. D., et al. (2004). Kv1.3 channel gene-targeted deletion produces "Super-Smeller Mice" with altered glomeruli, interacting scaffolding proteins, and biophysics. Neuron 41, 389-404. doi: 10.1016/S0896-6273(03)00844-4

Fadool, D. A., Tucker, K., Phillips, J. J., and Simmen, J. A. (2000). Brain insulin receptor causes activity-dependent current suppression in the olfactory bulb through multiple phosphorylation of Kv1.3. J. Neurophysiol. 83, 2332-2348.

Fujita, Y., Krause, G., Scheffner, M., Zechner, D., Leddy, H. E. M., Behrens, J., et al. (2002). Hakai, a c-Cbl-like protein, ubiquitinates and induces endocytosis of the E-cadherin complex. Nat. Cell Biol. 4, 222-231. doi: 10.1038/ncb758

Gyllberg, H., Löfgren, K., Lindegren, H., and Bedecs, K. (2006). Increased Src kinase level results in increased protein tyrosine phosphorylation in scrapie-infected neuronal cell lines. FEBS Lett. 580, 2603-2608. doi: 10.1016/j.febslet.2006.03.092

Halabisky, B., Friedman, D., Radojicic, M., and Strowbridge, B. W. (2000). Calcium influx through NMDA receptors directly evokes GABA release in olfactory bulb granule cells. J. Neurosci. 20, 5124-5134.

Hu, X., He, W., Diaconu, C., Tang, X., Kidd, G. J., Macklin, W. B., et al. (2008). Genetic deletion of BACE1 in mice affects remyelination of sciatic nerves. FASEB J. 22, 2970-2980. doi: 10.1096/fj.08-106666

Hu, X., Hicks, C. W., He, W., Wong, P., Macklin, W. B., Trapp, B. D., et al. (2006). Bacel modulates myelination in the central and peripheral nervous system. Nat. Neurosci. 9, 1520-1525. doi: 10.1038/nn1797

Ishiyama, N., Lee, S.-H., Liu, S., Li, G.-Y., Smith, M. J., Reichardt, L. F., et al. (2010). Dynamic and static interactions between p120 catenin and Ecadherin regulate the stability of cell-cell adhesion. Cell 141, 117-128. doi: 10.1016/j.cell.2010.01.017

Jiang, T., and Qiu, Y. (2003). Interaction between Src and a C-terminal proline-rich motif of Akt is required for Akt activation. J. Biol. Chem. 278, 15789-15793. doi: 10.1074/jbc.M212525200
Khosravani, H., Zhang, Y., Tsutsui, S., Hameed, S., Altier, C., Hamid, J., et al. (2008). Prion protein attenuates excitotoxicity by inhibiting NMDA receptors. J. Cell Biol. 181, 551-565. doi: 10.1083/jcb.200711002

Kitazawa, H., Yagi, T., Miyakawa, T., Niki, H., and Kawai, N. (1998). Abnormal synaptic transmission in the olfactory bulb of Fyn-kinase-deficient mice. J. Neurophysiol. 79, 137-142.

Kramer-Albers, E. M., and White, R. (2011). From axon-glial signalling to myelination: the integrating role of oligodendroglial Fyn kinase. Cell Mol. Life Sci. 68, 2003-2012. doi: 10.1007/s00018-010-0616-Z

Kroepfl, J. F., and Gardinier, M. V. (2001a). Identification of a basolateral membrane targeting signal within the cytoplasmic domain of myelin/oligodendrocyte glycoprotein. J. Neurochem. 77, 1301-1309. doi: 10.1046/j.1471-4159.2001.00343.x

Kroepfl, J. F., and Gardinier, M. V. (2001b). Mutually exclusive apicobasolateral sorting of two oligodendroglial membrane proteins, proteolipid protein and myelin/oligodendrocyte glycoprotein, in Madin-Darby canine kidney cells. J. Neurosci. Res. 66, 1140-1148. doi: 10.1002/jnr.10035

Lavezzari, G., Mccallum, J., Lee, R., and Roche, K. W. (2003). Differential binding of the AP-2 adaptor complex and PSD-95 to the C-terminus of the NMDA receptor subunit NR2B regulates surface expression. Neuropharmacology 45, 729-737. doi: 10.1016/S0028-3908(03)00308-3

Lee, G., Thangavel, R., Sharma, V. M., Litersky, J. M., Bhaskar, K., Fang, S. M., et al. (2004). Phosphorylation of tau by fyn: implications for Alzheimer's disease. J. Neurosci. 24, 2304-2312. doi: 10.1523/JNEUROSCI.4162-03.2004

Le Pichon, C. E., Valley, M. T., Polymenidou, M., Chesler, A. T., Sagdullaev, B. T., Aguzzi, A., et al. (2009). Olfactory behavior and physiology are disrupted in prion protein knockout mice. Nat. Neurosci. 12, 60-69. doi: 10.1038/nn.2238

Li, A., Christensen, H. M., Stewart, L. R., Roth, K. A., Chiesa, R., and Harris, D. A. (2007). Neonatal lethality in transgenic mice expressing prion protein with a deletion of residues 105-125. EMBO J. 26, 548-558. doi: 10.1038/sj.emboj.7601507

Li, C., Xiao, L., Liu, X., Yang, W., Shen, W., Hu, C., et al. (2013). A functional role of NMDA receptor in regulating the differentiation of oligodendrocyte precursor cells and remyelination. Glia 61, 732-749. doi: 10.1002/glia.22469

Linden, R., Martins, V. R., Prado, M. A., Cammarota, M., Izquierdo, I., and Brentani, R. R. (2008). Physiology of the prion protein. Physiol. Rev. 88, 673-728. doi: 10.1152/physrev.00007.2007

Liu, Y., Tao, Y. M., Woo, R. S., Xiong, W. C., and Mei, L. (2007). Stimulated ErbB4 internalization is necessary for neuregulin signaling in neurons. Biochem. Biophys. Res. Commun. 354, 505-510. doi: 10.1016/j.bbrc.2007.01.009

Lowell, C. A., and Soriano, P. (1996). Knockouts of Src-family kinases: stiff bones, wimpy $\mathrm{T}$ cells, and bad memories. Genes Dev. 10, 1845-1857. doi: 10.1101/gad.10.15.1845

Málaga-Trillo, E., and Sempou, E. (2009). PrPs: proteins with a purpose: lessons from the zebrafish. Prion 3, 129-133. doi: 10.4161/pri.3.3.9651

Málaga-Trillo, E., Solis, G. P., Schrock, Y., Geiss, C., Luncz, L., Thomanetz, V., et al. (2009). Regulation of embryonic cell adhesion by the prion protein. PLoS Biol. 7:e55. doi: 10.1371/journal.pbio.1000055

Maroteaux, L., Campanelli, J. T., and Scheller, R. H. (1988). Synuclein: a neuronspecific protein localized to the nucleus and presynaptic nerve terminal. J. Neurosci. 8, 2804-2815.

Martin-Lannerée, S., Hirsch, T. Z., Hernandez-Rapp, J., Halliez, S., Vilotte, J., Launay, J., et al. (2014). PrPC from stem cells to cancer. Front. Cell Dev. Biol. 2:55. doi: $10.3389 /$ fcell.2014.00055

Messa, M., Congia, S., Defranchi, E., Valtorta, F., Fassio, A., Onofri, F., et al. (2010). Tyrosine phosphorylation of synapsin I by Src regulates synaptic-vesicle trafficking. J. Cell Sci. 123, 2256-2265. doi: 10.1242/jcs.068445

Minami, S. S., Clifford, T. G., Hoe, H. S., Matsuoka, Y., and Rebeck, G. W. (2012). Fyn knock-down increases Abeta, decreases phospho-tau, and worsens spatial learning in 3xTg-AD mice. Neurobiol. Aging 33, 825.e815-825.e824. doi: 10.1016/j.neurobiolaging.2011.05.014

Miyashita, Y., and Ozawa, M. (2007). Increased internalization of p120-uncoupled E-cadherin and a requirement for a dileucine motif in the cytoplasmic domain for endocytosis of the protein. J. Biol. Chem. 282, 11540-11548. doi: 10.1074/jbc.M608351200

Morel, E., Fouquet, S., Chateau, D., Yvernault, L., Frobert, Y., Pincon-Raymond, M., et al. (2004). The cellular prion protein PrPc is expressed in human enterocytes in cell-cell junctional domains. J. Biol. Chem. 279, 1499-1505. doi: 10.1074/jbc.M308578200 
Morel, E., Fouquet, S., Strup-Perrot, C., Pichol Thievend, C., Petit, C., Loew, D., et al. (2008). The cellular prion protein $\operatorname{PrP}(c)$ is involved in the proliferation of epithelial cells and in the distribution of junction-associated proteins. PLoS ONE 3:e3000. doi: 10.1371/journal.pone.0003000

Morse, W. R., Whitesides, J. G. 3rd., Lamantia, A. S., and Maness, P. F. (1998). p59fyn and pp60c-src modulate axonal guidance in the developing mouse olfactory pathway. J. Neurobiol. 36, 53-63. doi: 10.1002/(SICI)10974695(199807)36:1<53::AID-NEU5>3.0.CO;2-9

Mouillet-Richard, S., Ermonval, M., Chebassier, C., Laplanche, J. L., Lehmann, S., Launay, J. M., et al. (2000). Signal transduction through prion protein. Science 289, 1925-1928. doi: 10.1126/science.289.5486.1925

Moya, K. L., Sales, N., Hassig, R., Creminon, C., Grassi, J., and Di Giamberardino, L. (2000). Immunolocalization of the cellular prion protein in normal brain. Microsc. Res. Tech. 50, 58-65. doi: 10.1002/1097-0029(20000701)50:1<58::AIDJEMT9>3.0.CO;2-5

Nixon, R. (2005). Prion-associated increases in Src-family kinases. J. Biol. Chem. 280, 2455. doi: 10.1074/jbc.M410883200

Ondrusova, L., Reda, J., Zakova, P., and Tuhackova, Z. (2013). Inhibition of mTORC1 by SU6656, the selective Src kinase inhibitor, is not accompanied by activation of Akt/PKB signalling in melanoma cells. Folia Biol. (Praha) 59, 162-167.

Pantera, B., Bini, C., Cirri, P., Paoli, P., Camici, G., Manao, G., et al. (2009). PrPc activation induces neurite outgrowth and differentiation in PC12 cells: role for caveolin-1 in the signal transduction pathway. J. Neurochem. 110, 194-207. doi: 10.1111/j.1471-4159.2009.06123.x

Passet, B., Halliez, S., Beringue, V., Laude, H., and Vilotte, J. L. (2013). The prion protein family: looking outside the central nervous system. Prion 7, 127-130. doi: $10.4161 /$ pri.22851

Peretz, A., Sobko, A., and Attali, B. (1999). Tyrosine kinases modulate K+ channel gating in mouse Schwann cells. J. Physiol. 519(Pt 2), 373-384. doi: 10.1111/j.1469-7793.1999.0373m.x

Reynolds, A. B. (2010). Exposing p120 catenin's most intimate affair. Cell 141, 20-22. doi: 10.1016/j.cell.2010.03.022

Roskoski, R. Jr. (2004). Src protein-tyrosine kinase structure and regulation. Biochem. Biophys. Res. Commun. 324, 1155-1164. doi: 10.1016/j.bbrc.2004.09.171

Roskoski, R. Jr. (2005). Src kinase regulation by phosphorylation and dephosphorylation. Biochem. Biophys. Res. Commun. 331, 1-14. doi: 10.1016/j.bbrc.2005.03.012

Salter, M. W., and Kalia, L. V. (2004). Src kinases: a hub for NMDA receptor regulation. Nat. Rev. Neurosci. 5, 317-328. doi: 10.1038/nrn1368

Santuccione, A., Sytnyk, V., Leshchyns'ka, I., and Schachner, M. (2005). Prion protein recruits its neuronal receptor NCAM to lipid rafts to activate p59fyn and to enhance neurite outgrowth. J. Cell Biol. 169, 341-354. doi: $10.1083 /$ jcb. 200409127

Sanz-Clemente, A., Nicoll, R. A., and Roche, K. W. (2013). Diversity in NMDA receptor composition: many regulators, many consequences. Neuroscientist 19, 62-75. doi: 10.1177/1073858411435129

Schachner, M., and Bartsch, U. (2000). Multiple functions of the myelin-associated glycoprotein MAG (siglec-4a) in formation and maintenance of myelin. Glia 29, 154-165. doi: 10.1002/(SICI) 1098-1136(20000115)29:2<154::AIDGLIA9>3.0.CO;2-3

Schubert, W., Prior, R., Weidemann, A., Dircksen, H., Multhaup, G., Masters, C. L., et al. (1991). Localization of Alzheimer beta A4 amyloid precursor protein at central and peripheral synaptic sites. Brain Res. 563, 184-194. doi: 10.1016/0006-8993(91)91532-6

Senatore, A., Colleoni, S., Verderio, C., Restelli, E., Morini, R., Condliffe, S. B., et al. (2012). Mutant PrP suppresses glutamatergic neurotransmission in cerebellar granule neurons by impairing membrane delivery of VGCC alpha(2)delta-1 Subunit. Neuron 74, 300-313. doi: 10.1016/j.neuron.2012.02.027

Shirazi, S. K., and Wood, J. G. (1993). The protein tyrosine kinase, fyn, in Alzheimer's disease pathology. Neuroreport 4, 435-437. doi: 10.1097/00001756199304000-00024

Silverman, L., Sudol, M., and Resh, M. D. (1993). Members of the src family of nonreceptor tyrosine kinases share a common mechanism for membrane binding. Cell Growth Differ. 4, 475-482.

Sobko, A., Peretz, A., and Attali, B. (1998). Constitutive activation of delayedrectifier potassium channels by a src family tyrosine kinase in Schwann cells. EMBO J. 17, 4723-4734. doi: 10.1093/emboj/17.16.4723
Solomon, I. H., Huettner, J. E., and Harris, D. A. (2010). Neurotoxic mutants of the prion protein induce spontaneous ionic currents in cultured cells. J. Biol. Chem. 285, 26719-26726. doi: 10.1074/jbc.M110.134619

Sperber, B. R., Boyle-Walsh, E. A., Engleka, M. J., Gadue, P., Peterson, A. C., Stein, P. L., et al. (2001). A unique role for Fyn in CNS myelination. J. Neurosci. 21, 2039-2047.

Spielhaupter, C., and Schatzl, H. M. (2001). PrPC directly interacts with proteins involved in signaling pathways. J. Biol. Chem. 276, 44604-44612. doi: 10.1074/jbc.M103289200

Steele, A. D., Emsley, J. G., Ozdinler, P. H., Lindquist, S., and Macklis, J. D. (2006). Prion protein $(\mathrm{PrPc})$ positively regulates neural precursor proliferation during developmental and adult mammalian neurogenesis. Proc. Natl. Acad. Sci. U.S.A. 103, 3416-3421. doi: 10.1073/pnas.0511290103

Steele, A. D., Lindquist, S., and Aguzzi, A. (2007). The prion protein knockout mouse: a phenotype under challenge. Prion 1, 83-93. doi: 10.4161/pri.1.2.4346

Thomas, S. M., and Brugge, J. S. (1997). Cellular functions regulated by Src family kinases. Annu. Rev. Cell Dev. Biol. 13, 513-609. doi: 10.1146/annurev.cellbio.13.1.513

Thoreson, M. A., Anastasiadis, P. Z., Daniel, J. M., Ireton, R. C., Wheelock, M. J., Johnson, K. R., et al. (2000). Selective uncoupling of p120(ctn) from Ecadherin disrupts strong adhesion. J. Cell Biol. 148, 189-202. doi: 10.1083/jcb. 148.1.189

Tiran, Z., Peretz, A., Sines, T., Shinder, V., Sap, J., Attali, B., et al. (2006). Tyrosine phosphatases epsilon and alpha perform specific and overlapping functions in regulation of voltage-gated potassium channels in Schwann cells. Mol. Biol. Cell 17, 4330-4342. doi: 10.1091/mbc.E06-02-0151

Um, J. W., Nygaard, H. B., Heiss, J. K., Kostylev, M. A., Stagi, M., Vortmeyer, A., et al. (2012). Alzheimer amyloid-beta oligomer bound to postsynaptic prion protein activates Fyn to impair neurons. Nat. Neurosci. 15, 1227-1235. doi: 10.1038/nn.3178

Umemori, H., Kadowaki, Y., Hirosawa, K., Yoshida, Y., Hironaka, K., Okano, H., et al. (1999). Stimulation of myelin basic protein gene transcription by Fyn tyrosine kinase for myelination. J. Neurosci. 19, 1393-1397.

Umemori, H., Sato, S., Yagi, T., Aizawa, S., and Yamamoto, T. (1994). Initial events of myelination involve Fyn tyrosine kinase signalling. Nature 367, 572-576. doi: $10.1038 / 367572 \mathrm{a} 0$

Vojtechova, M., Tureckova, J., Kucerova, D., Sloncova, E., Vachtenheim, J., and Tuhackova, Z. (2008). Regulation of mTORC1 signaling by Src kinase activity is Akt1-independent in RSV-transformed cells. Neoplasia 10, 99-107. doi: 10.1593/neo.07905

White, R., Gonsior, C., Kramer-Albers, E. M., Stohr, N., Huttelmaier, S., and Trotter, J. (2008). Activation of oligodendroglial Fyn kinase enhances translation of mRNAs transported in hnRNP A2-dependent RNA granules. J. Cell Biol. 181, 579-586. doi: 10.1083/jcb.200706164

White, R., and Kramer-Albers, E. M. (2014). Axon-glia interaction and membrane traffic in myelin formation. Front. Cell. Neurosci. 7:284. doi: 10.3389/fncel.2013.00284

Wilde, A., Beattie, E. C., Lem, L., Riethof, D. A., Liu, S. H., Mobley, W. C., et al. (1999). EGF receptor signaling stimulates SRC kinase phosphorylation of clathrin, influencing clathrin redistribution and EGF uptake. Cell 96, 677-687. doi: 10.1016/S0092-8674(00)80578-4

Winterstein, C., Trotter, J., and Kramer-Albers, E. M. (2008). Distinct endocytic recycling of myelin proteins promotes oligodendroglial membrane remodeling. J. Cell. Sci. 121, 834-842. doi: 10.1242/jcs.022731

Yagi, T., Aizawa, S., Tokunaga, T., Shigetani, Y., Takeda, N., and Ikawa, Y. (1993). A role for Fyn tyrosine kinase in the suckling behaviour of neonatal mice. Nature 366, 742-745. doi: 10.1038/366742a0

Zhang, C. C., Steele, A. D., Lindquist, S., and Lodish, H. F. (2006). Prion protein is expressed on long-term repopulating hematopoietic stem cells and is important for their self-renewal. Proc. Natl. Acad. Sci. U.S.A. 103, 2184-2189. doi: 10.1073/pnas.0510577103

Zimmerman, B., Simaan, M., Lee, M. H., Luttrell, L. M., and Laporte, S. A. (2009). c-Src-mediated phosphorylation of AP-2 reveals a general mechanism for receptors internalizing through the clathrin pathway. Cell Signal 21, 103-110. doi: 10.1016/j.cellsig.2008.09.013

Zou, L., Wang, Z., Shen, L., Bao, G. B., Wang, T., Kang, J. H., et al. (2007). Receptor tyrosine kinases positively regulate BACE activity and Amyloid-beta production through enhancing BACE internalization. Cell Res. 17, 389-401. doi: $10.1038 / \mathrm{cr} .2007 .5$ 
Conflict of Interest Statement: The authors declare that the research was conducted in the absence of any commercial or financial relationships that could be construed as a potential conflict of interest.

Received: 16 August 2014; paper pending published: 05 September 2014; accepted: 02 October 2014; published online: 28 October 2014.

Citation: Ochs K and Málaga-Trillo E (2014) Common themes in PrP signaling: the Src remains the same. Front. Cell Dev. Biol. 2:63. doi: 10.3389/fcell.2014.00063
This article was submitted to Cell Death and Survival, a section of the journal Frontiers in Cell and Developmental Biology.

Copyright (C) 2014 Ochs and Málaga-Trillo. This is an open-access article distributed under the terms of the Creative Commons Attribution License (CC BY). The use, distribution or reproduction in other forums is permitted, provided the original author(s) or licensor are credited and that the original publication in this journal is cited, in accordance with accepted academic practice. No use, distribution or reproduction is permitted which does not comply with these terms. 